\title{
A Case of a Reversible Neurologic Adverse Reaction to Apixaban Confirmed by Re-Challenge
}

\author{
James A. Josyln ${ }^{a}$, Furqan H. Khattak ${ }^{a, b, ~ c}$, Stephen A. Geraci ${ }^{\mathrm{a}, ~ b, ~ c, ~ d, ~ e ~}$
}

\begin{abstract}
Post-marketing reporting of adverse drug events is essential for new medications, as pre-FDA approval studies lack sufficient subject numbers to detect signals for rare events. Prescriptions for the novel oral anticoagulant factor Xa inhibitors (rivaroxaban, apixaban, edoxaban) have equaled or exceeded those for vitamin $\mathrm{K}$ antagonists in many clinical settings requiring chronic anticoagulation, and those of injectable heparins for deep vein thrombosis prophylaxis. We report the case of a 60 -year-old woman followed for permanent atrial fibrillation who was prescribed apixaban. She rapidly developed worsening neurologic symptoms of imbalance and non-vertiginous dizziness preventing her from walking, headache, diplopia, and confusion/disorientation. Her symptoms began to resolve after stopping the drug, with return to baseline function within $72 \mathrm{~h}$. Unbeknownst to her cardiology care team, the patient chose to re-challenge herself with apixaban at the same dose, producing identical symptoms and again total symptom resolution within $24 \mathrm{~h}$ of drug discontinuation. When seen by her physician, her physical examination was unchanged from her pre-treatment baseline. Symptoms did not recur when switched to rivaroxaban therapy.
\end{abstract}

Keywords: NOAC; DOAC; Apixaban; Adverse drug reaction; Neurologic

\section{Introduction}

New oral anticoagulants are now commonly prescribed in place of traditional vitamin $\mathrm{K}$ antagonists. As they are relatively new on the market, the extent of adverse drug reactions continues to be characterized. We present a case of a patient

Manuscript submitted March 2, 2018, accepted March 30, 2018

a Quillen College of Medicine, Johnson City, TN, USA

${ }^{b}$ Division of Cardiology, Quillen College of Medicine, Johnson City, TN, USA 'Department of Internal Medicine, Quillen College of Medicine, Johnson City, TN, USA

dSection of Medical Education, James H. Quillen College of Medicine, Johnson City, TN, USA

${ }^{\mathrm{e}}$ Corresponding Author: Stephen A. Geraci, Department of Medicine, Quillen College of Medicine, PO Box 70622, Johnson City, TN 37614, USA.

Email: geraci@etsu.edu

doi: https://doi.org/10.14740/jocmr3394w treated with apixaban for atrial fibrillation stroke prophylaxis, who suffered complex neurologic symptoms which resolved completely with drug discontinuation. She re-challenged herself with apixaban, with recurrence of symptoms and, again, resolution after stopping the drug. We discuss the categorizations of adverse drug events and attempt to apply these to our patient's case and explore possible mechanisms.

\section{Case Report}

Our patient was a 60 -year-old female followed by cardiology for permanent atrial fibrillation. Her other chronic medical problems included morbid obesity (body mass index $=49$ ), dyslipidemia, hypertension, non-alcoholic steatohepatitis, hypothyroidism, depression, anxiety, congenital myopathy of unknown etiology, and uncharacterized polycythemia for which she received monthly phlebotomies. Past surgical history included cholecystectomy, hysterectomy, knee replacement, tonsillectomy, and transvaginal taping. Her joint and muscle diseases required her to walk with a walker. She was a divorced mother of two and lived alone, with a 14 pack-year smoking history (stopped 7 years ago). She had drunk approximately four cups of coffee each day but denied any alcohol consumption or use of non-prescribed or recreational drugs. Her family history was significant for cancer, diabetes mellitus, hypertension, coronary heart disease, heart failure and chronic kidney disease. Her long-term oral medications at the index visit included aspirin $325 \mathrm{mg}$ once daily, bupropion 150 $\mathrm{mg}$ once daily for depression, metoprolol tartrate $50 \mathrm{mg}$ every $12 \mathrm{~h}$ and extended-release verapamil $120 \mathrm{mg}$ every $12 \mathrm{~h}$ for ventricular rate control and hypertension treatment, levothyroxine $125 \mu \mathrm{g}$ daily for hypothyroidism, and diazepam $5 \mathrm{mg}$ by mouth three times daily as needed. She recounted the following adverse drug reactions in the past: aripiprazole: muscle twitching; venlafaxine: palpitations; pregabalin: lower extremity edema; gabapentin: gastritis; niacin: torso and upper limb pruritic rash; lansoprazole: heart palpitations; atorvastatin: muscle pain and weakness; lisinopril: angioedema.

Her most recent laboratory studies prior to starting apixaban including a complete metabolic profile, complete blood count, serum ferritin, fasting lipids, and thyroid stimulating hormone were normal except as noted (Table 1).

The patient had refused to take warfarin for stroke prophylaxis for many years, and had never taken any oral anticoagulants previously. She had never suffered a clinical embolus, and her $\mathrm{CHA}_{2} \mathrm{DS}_{2}$ VASc score was 2. After long, multiple dis- 
Table 1. Patient's Abnormal Laboratory Values Prior to Starting Apixaban

\begin{tabular}{lll}
\hline Test & Patient value & Normal \\
\hline Estimated glomerular filtration rate $(\mathrm{mL} / \mathrm{min})$ & 70 & 90 \\
Aspartate aminotransferase $(\mathrm{U} / \mathrm{L})$ & 45 & $11-38$ \\
Serum ferritin $(\mathrm{ng} / \mathrm{mL})$ & 44 & $10-291$ \\
Total cholesterol $(\mathrm{mg} / \mathrm{dL})$ & 239 & $<200$ \\
Triglycerides $(\mathrm{mg} / \mathrm{dL})$ & 153 & $<150$ \\
High density lipoprotein $(\mathrm{mg} / \mathrm{dL})$ & 40 & $\geq 50$ (female) \\
Low density lipoprotein $(\mathrm{mg} / \mathrm{dL})$ & 169 & $<100$ \\
\hline
\end{tabular}

cussions she agreed to take apixaban (Eliquis ${ }^{\circledR}$, Bristol-Myers Squibb, New York, New York) $5 \mathrm{mg}$ twice daily and stopped aspirin at her index office visit. No other changes were made in her medical regimen at that time.

She reported that shortly after taking her first dose of apixaban she began experiencing a "strange sensation" that progressed to a loss of balance. She continued taking her medication as prescribed. Over the following 2 days, her balance worsened and she began to experience non-vertiginous dizziness without syncope. On treatment day 3 she developed a severe pressure-type headache that encompassed her entire head. By treatment day 5 she began to experience intermittent diplopia. She became disoriented and confused to the degree that she became lost near her house where she had lived her entire life. Her loss of balance then progressed to the point that she could not leave the house and needed to crawl from bed to bathroom. On day 11 of apixaban therapy, she telephoned the prescribing cardiologist to report her symptoms. She denied muscle pain, weakness, joint pain, wheezing, rash, pruritus, lip or mouth swelling, or palpitations. As she declined immediate ambulance transfer to the local hospital, she was instructed to discontinue the medication immediately and to come to the office for evaluation as soon as possible. Upon discontinuing apixaban, her symptoms began to resolve. Three days later, she reported complete symptom resolution and a return to her baseline function. She remained off the medication for 10 days after which, without advising her physician, she re-started apixaban (self rechallenge) at the same dose. She reported that the symptoms recurred in exactly the same manner as they had when first starting apixaban. After 5 days on apixaban, she discontinued the medication, with complete resolution of symptoms within $24 \mathrm{~h}$. When she presented to cardiology clinic, she reported this narrative. Physical exam at that time was unchanged from her pretreatment baseline, including a normal neurologic exam. As her symptoms had resolved completely, and with her recurrenceafter-re-challenge and resolution history, no CNS imaging was performed. Her anticoagulant was changed to rivaroxaban 15 mg twice daily. After 4 months of treatment, she had experienced no similar or other adverse symptoms.

\section{Discussion}

New (novel)/direct oral anticoagulants (NOACs, DOACs) that act through reversible factor Xa inhibition (rivaroxaban, apixa- ban, edoxaban) are now commonly used in lieu of warfarin in a number of clinical settings. Primary clinical trials contributing to their Food and Drug Administration (FDA) approvals also assessed for safety signals for hemorrhage risk. In comparison to warfarin, these drugs appeared therapeutically non-inferior, and in some cases superior (for non-valvular atrial fibrillation-related stroke prophylaxis, deep vein thrombosis (DVT) prophylaxis, and DVT/pulmonary embolism treatment) and as safe or safer regarding major bleeding (intracranial, gastrointestinal) risk [1-6]. Some now have a role in secondary cardiovascular prevention [7], yet none appear effective for all (e.g., prosthetic valve thromboembolism prophylaxis) clinical needs $[8,9]$. These drugs do not require regular blood monitoring, and aside from the additive effects of other types of anticoagulant/antiplatelet agents, have far fewer drug-drug interactions (CYP 3A4 inhibitors/inducers [10, 11], calcineurin inhibitors $[12,13]$, P-glycoprotein inhibitors [14, 15], non-steroidal antiinflammatory drugs $[16,17])$ than does warfarin, and no reported interactions with food save grapefruit juice [18]. They are easily dosed once or twice daily by strategy with few dosing adjustments required for patient-specific variables (renal dysfunction, extreme patient age, low body weight) [13]. All are not advised in patients with severe liver disease.

Apixaban's pharmacokinetic profile has been described [19] including a peak single dose concentration at about $3 \mathrm{~h}$; and an apparent $\beta$ half-life of about $12 \mathrm{~h}$ after multiple dosing. The pharmacodynamic effects within a 10-fold dose range (2.5 - $25 \mathrm{mg}$ twice daily) are concentration-related with low to moderate variability. Of note, $\mathrm{AUC}_{\text {tau }}$ between day 1 and day 7 administration of a $5 \mathrm{mg}$ twice daily dose increased by $75 \%$. The drug is approximately $50 \%$ bioavailable after recommended dosing. Approximately $25 \%$ of an oral dose is excreted as metabolites. O-demethylation and hydroxylation is primarily performed by CYP 3A4 although other cytochrome P450 enzymes (1A2, 2C8, 2C9, 2C19, 2J2) contribute to its metabolism. Apixaban is also a substrate for the P-glycoprotein efflux transporter. Based upon these facts, the manufacturer recommends that the apixaban dose be limited to $2.5 \mathrm{mg}$ twice daily in patients on strong dual inhibitors of these proteins [11]. Despite these findings, no increase in bleeding complications were found when apixaban was co-administered with verapamil (adjusted risk ratio with versus without verapamil, 0.95 (99\% CI 0.51, 1.77) [20]. Apixaban does not appear to inhibit or induce CYP enzymes or the P-glycoprotein transporter.

The vast majority of adverse drug event (ADEs) reports 
for apixaban focus, as expected, on one or more manifestations of heightened bleeding risk. Reports have also been published documenting rare idiosyncratic drug-induced liver injury, which is usually but not always reversible with drug discontinuation [21]. However, an extensive search of the peer-reviewed literature (PubMed, Google/Google Scholar) failed to identify any neurologic adverse events due to apixaban, save those associated with hemorrhage or hematoma formation. The FDA's Adverse Reporting System Public Dashboard (accessed January 25, 2018) of reports received from 2011 to January 2018 listed 19 reports of diplopia, 163 of confusion, 27 of disorientation, 894 of dizziness, 718 of headache, and 86 of balance disorders [22]. As stated on this official web site, these reports may have significant "...limitations, including incomplete, inaccurate, untimely, unverified information..." and that "information on this website does not confirm a causal relationship between the drug product and the reported adverse event(s)" [22]. A major drug reference database [13] lists pre-syncope (considered a cardiovascular effect) in $<1 \%$ of patients with non-valvular atrial fibrillation taking apixaban based on two large randomized trials/registries (ARISTOTLE [2], AVERROES [23]), but further details are not available to assess whether these patients might in fact have had complication syndromes similar to that of our patient. Other sources [24] list dizziness, confusion and decreased alertness, or headaches [25] but provide no supporting references, details of observed cases, or descriptions of whether a combination of these symptoms were present in any individual patients.

Several aspects of this case strongly suggest apixaban as the causative agent: 1) Suggestion of possible similar reports available on the FDA Surveillance Database; 2) Symptoms were not present prior to drug administration; 3) Symptoms began shortly after initial administration of this newly-prescribed agent; 4) Symptoms progressively worsened with continued drug consumption; 5) Symptoms resolved rapidly with drug discontinuation; 6) Symptoms recurred with (patient-initiated) re-challenge; and 7) The second episode of symptoms again resolved with drug discontinuation. CNS imaging was not considered cost-beneficial for this patient at the time of physical presentation, as the history of reproducible and totally resolving clinical symptoms made vascular or hemorrhagic events extraordinarily unlikely.

To our knowledge, this is the first case reported in the peerreviewed literature of this particular adverse event syndrome from apixaban, as well as the first to include a drug re-challenge further supporting a causative association with the drug. Adverse drug reactions are generally classified into six categories: A) dose-dependent, augmentations of known pharmacologic activities; B) non-dose-dependent, unpredictable events not related to known pharmacology of the drug (includes immunologic/hypersensitivity and idiosyncratic reactions; implies host susceptibility through genetics or other mechanisms); C) chronic (dose- and time-related) reactions; D) delayed (timerelated) reactions; E) withdrawal phenomena with drug discontinuation; and F) unexpected failure of therapy [26]. Although the clinical timeline bore some association with the drug's known pharmacokinetics, and possible alterations in half-life by concomitantly administered verapamil could have influenced this relationship, this relationship was not consistent and we therefore concluded that our patient's reaction was most likely a category B (idiosyncratic/hypersensitivity) reaction. Of the four types of hypersensitivity reactions, this patient's reaction is most consistent with Type I (immediate hypersensitivity reaction), though she had no history of prior exposure and lacked other symptoms of histamine or eicosanoid actions [27]. Using the World Health Organization-Uppsala Monitoring Centre causality assessment scale [28], this patient's reaction falls between the "Probable/likely" and "Certain" categories, with the latter identified largely due to the positive re-challenge criteria [29]. Using the Naranjo Adverse Drug Reaction Probability Scale, our patient generates 5 points, placing this reaction in the "probable" causality category [30].

Few publications have attempted to summarize mechanisms of neurological adverse drug reactions. Our patient's symptoms were not consistent with neurologic drug side effects associated with specific syndromes with known mechanisms (cerebrovascular events, elevated cholinergic activity, serotonin syndrome, idiopathic intracranial hypertension, neuroleptic malignant syndrome, akathisia, chorea, tardive syndromes, dystonic reactions, dystonia, tremor, parkinsonism) [31]. She had no symptoms consistent with a true immunologic reaction. Hence, our patient's reaction does not fit with available descriptions of such reactions from other drugs.

The exact mechanism of our patient's adverse reaction is unclear, as details appear to cross standard categories. However, as these more convenient and likely superior, safer drugs become the standard of care for many large patient populations requiring chronic anticoagulation, post-marketing peer-reviewed reports of idiopathic adverse drug reactions to NOACs, such as that experienced by our patient, are critical.

\section{Funding}

No funding from any source or agency from any sector was received for this work.

\section{Consent}

Verbal informed consent was obtained from the patient for her anonymized information to be published in this article.

\section{Conflict of Interest}

All authors declare that they have no real or apparent financial or intellectual conflict of interest or relations with industry relevant to the content of this manuscript.

\section{References}

1. Granger CB, Alexander JH, McMurray JJ, Lopes RD, Hylek EM, Hanna M, Al-Khalidi HR, et al. Apixaban versus warfarin in patients with atrial fibrillation. N Engl J Med. 2011;365(11):981-992. 
2. Patel MR, Mahaffey KW, Garg J, Pan G, Singer DE, Hacke W, Breithardt G, et al. Rivaroxaban versus warfarin in nonvalvular atrial fibrillation. N Engl J Med. 2011;365(10):883-891.

3. Giugliano RP, Ruff CT, Braunwald E, Murphy SA, Wiviott SD, Halperin JL, Waldo AL, et al. Edoxaban versus warfarin in patients with atrial fibrillation. N Engl J Med. 2013;369(22):2093-2104.

4. Lassen MR, Raskob GE, Gallus A, Pineo G, Chen D, Hornick $\mathrm{P}$, investigators A-. Apixaban versus enoxaparin for thromboprophylaxis after knee replacement (ADVANCE-2): a randomised double-blind trial. Lancet. 2010;375(9717):807-815.

5. Agnelli G, Buller HR, Cohen A, Curto M, Gallus AS, Johnson M, Masiukiewicz U, et al. Oral apixaban for the treatment of acute venous thromboembolism. N Engl J Med. 2013;369(9):799-808.

6. The EINSTEIN-PE Investigators, Buller HR, Prins MH, Lensin AW, Decousus H, Jacobson BF, Minar E, et al. Oral rivaroxaban for the treatment of symptomatic pulmonary embolism. N Engl J Med. 2012;366(14):12871297.

7. Eikelboom JW, Connolly SJ, Bosch J, Dagenais GR, Hart RG, Shestakovska O, Diaz R, et al. Rivaroxaban with or without aspirin in stable cardiovascular disease. N Engl J Med. 2017;377(14):1319-1330.

8. Nishimura RA, Otto CM, Bonow RO, Carabello BA, Erwin JP, 3rd, Guyton RA, O'Gara PT, et al. 2014 AHA/ ACC guideline for the management of patients with valvular heart disease: a report of the American College of Cardiology/American Heart Association Task Force on practice guidelines. Circulation. 2014;129(23):e521-643.

9. Nishimura RA, Otto CM, Bonow RO, Carabello BA, Erwin JP, 3rd, Fleisher LA, Jneid H, et al. 2017 AHA/ACC Focused Update of the 2014 AHA/ACC Guideline for the management of patients with valvular heart disease: a report of the American College of Cardiology/American Heart Association Task Force on clinical practice guidelines. J Am Coll Cardiol. 2017;70(2):252-289.

10. Frost CE, Byon W, Song Y, Wang J, Schuster AE, Boyd RA, Zhang D, et al. Effect of ketoconazole and diltiazem on the pharmacokinetics of apixaban, an oral direct factor Xa inhibitor. Br J Clin Pharmacol. 2015;79(5):838-846.

11. Eliquis (apixaban) Package insert, available at: https:// www.eliquis.com/eliquis/hcp?cid=sem_74382\&ovl=isi, accessed February 7, 2018.

12. Vanhove T, Spriet I, Annaert P, Maertens J, Van Cleemput J, Vos R, Kuypers D. Effect of the direct oral anticoagulants rivaroxaban and apixaban on the disposition of calcineurin inhibitors in transplant recipients. Ther Drug Monit. 2017;39(1):77-82.

13. Micromedix ${ }^{\circledR}$ Solutions. Truven health analytics. Available at http://www.micromedexsolutions.com/micromedex2/librarian/. Accessed February 7, 2018.

14. Stollberger C, Finsterer J. Relevance of P-glycoprotein in stroke prevention with dabigatran, rivaroxaban, and apixaban. Herz. 2015;40(Suppl 2):140-145.

15. Wessler JD, Grip LT, Mendell J, Giugliano RP. The Pglycoprotein transport system and cardiovascular drugs.
J Am Coll Cardiol. 2013;61(25):2495-2502.

16. Forbes HL, Polasek TM. Potential drug-drug interactions with direct oral anticoagulants in elderly hospitalized patients. Ther Adv Drug Saf. 2017;8(10):319-328.

17. Frost C, Shenker A, Gandhi MD, Pursley J, Barrett YC, Wang J, Zhang D, et al. Evaluation of the effect of naproxen on the pharmacokinetics and pharmacodynamics of apixaban. Br J Clin Pharmacol. 2014;78(4):877-885.

18. Pirmohamed M. Drug-grapefruit juice interactions: two mechanisms are clear but individual responses vary. BMJ. 2013;346:f1.

19. Frost C, Nepal S, Wang J, Schuster A, Byon W, Boyd RA, Yu Z, et al. Safety, pharmacokinetics and pharmacodynamics of multiple oral doses of apixaban, a factor Xa inhibitor, in healthy subjects. Br J Clin Pharmacol. 2013;76(5):776-786.

20. Chang SH, Chou IJ, Yeh YH, Chiou MJ, Wen MS, Kuo CT, See LC, et al. Association between use of non-vitamin $\mathrm{K}$ oral anticoagulants with and without concurrent medications and risk of major bleeding in nonvalvular atrial fibrillation. JAMA. 2017;318(13):1250-1259.

21. Liakoni E, Ratz Bravo AE, Krahenbuhl S. Hepatotoxicity of New Oral Anticoagulants (NOACs). Drug Saf. 2015;38(8):711-720.

22. Food and Drug Administration Adverse Reporting System Public Dashboard: https://fis.fda.gov/ sense/app/777e9f4d-0cf8-448e-8068-f564c31baa25/ sheet/7a47a261-d58b-4203-a8aa-6d3021737452/state/ analysis. Accessed January 25, 2018.

23. Connolly SJ, Eikelboom J, Joyner C, Diener HC, Hart R, Golitsyn S, Flaker G, et al. Apixaban in patients with atrial fibrillation. N Engl J Med. 2011;364(9):806-817.

24. Drugs.com. Available at: https://www.drugs.com/sfx/ apixaban-side-effects.html. Accessed February 8, 2018.

25. MedlinePlus. U.S. National Library of Medicine. Available at: https://medlineplus.gov/druginfo/meds/a613032. html\#side-effects. Accessed February 8, 2018.

26. Edwards IR, Aronson JK. Adverse drug reactions: definitions, diagnosis, and management. Lancet. 2000;356(9237):1255-1259.

27. Immunology. In: Carroll KC, Hobden JA, Miller S, Morse SA, Mietzner TA, Detrick B, Mitchell TG, McKerrow JH, Sakanari JA. eds. Jawetz, Melnick \& Adelberg's Medical Microbiology, 27e. New York, NY: McGraw-Hill; http:// accessmedicine.mhmedical.com/content.aspx?bookid=1 551\&sectionid=94105968. Accessed February 09, 2018.

28. Zaki SA. Adverse drug reaction and causality assessment scales. Lung India. 2011;28(2):152-153.

29. Schatz SN, Weber RJ. Adverse Drug Reactions. PSAP 2015, CNS/Pharmacy Practice, pp. 5-26. https://www. accp.com/docs/bookstore/psap/2015B2.SampleChapter. pdf. Accessed February 8, 2018.

30. Naranjo CA, Busto U, Sellers EM, Sandor P, Ruiz I, Roberts EA, Janecek E, et al. A method for estimating the probability of adverse drug reactions. Clin Pharmacol Ther. 1981;30(2):239-245.

31. Grosset KA, Grosset DG. Prescribed drugs and neurological complications. J Neurol Neurosurg Psychiatry. 2004;75(Suppl 3):iii2-8. 